\title{
Enteropathogenic Esch. coli gastroenteritis in premature infants and children treated with fosfomycin
}

\author{
F. BAQUERO, T. CAÑEDO, A. RODRIGUEZ, and E. JASO \\ Clínica Infantil 'La Paz', Departamento de Pediatria and Servicio de Microbiología de la C.S. 'La Paz', \\ Universidad Autónoma de Madrid; and Instituto de Farmacología Española, Madrid
}

\begin{abstract}
Baquero, F., Cañedo, T., Rodriguez, A., and Jaso, E. (1975). Archives of Disease in Childhood, 50, 367. Enteropathogenic Esch. coli gastroenteritis in premature infants and children treated with fosfomycin. Forty-two infants, some premature, with enteropathogenic Esch. coli (EPEC) gastroenteritis were treated with an oral suspension of fosfomycin in a dose of 100 and $200 \mathrm{mg} / \mathrm{kg}$ per day. After the treatment there were 11 secondary clinical infections (6 reinfections and 5 relapses) which received a second treatment with fosfomycin. In total, 53 treatments were made with fosfomycin and in $92 \%$ of the cases there was both clinical and bacteriological cure. $93 \%$ of the EPEC strains were sensitive to fosfomycin in vitro, their minimum inhibitory concentrations being $<64 \mu \mathrm{g} / \mathrm{ml}$. The concentration of fosfomycin in blood and faeces was assayed by a diffusion plate microbiological method in a group of these children, showing that this antibiotic is partly absorbed and the rest eliminated in the faeces, where its concentration was found to be very high. Tolerance of the product was good, and there were neither toxic nor side effects.
\end{abstract}

Fosfomycin is a new wide spectrum antibiotic described by Hendlin et al. (1969) and Stapley et al. (1970). It is very active in vitro against Esch. coli (Zimmerman et al., 1970; Kestle and Kirby, 1970; Martin et al., 1970; Moreno-Lopez et al., 1971) and has practically no toxicity (Miller et al., 1970). The absorption of an oral dose in man is approximately 30 to $40 \%$ (Rodriguez and Mata, 1968-1969; Foltz, Wallick, and Rosenblum, 1970). The absence of toxicity and the high acitivity against Esch. coli made us try this new antibiotic on a group of 39 premature babies and infants with gastroenteritis and 3 carriers of enteropathogenic Esch. coli (EPEC).

\section{Material and methods}

Patients. Table I shows the age and sex of the 42 children studied. $90 \%$ were less than 3 months old and $40 \%$ were premature. 39 of them had diarrhoea with two previous stool cultures positive for EPEC. It is important to emphasize that $76 \%$ of the children were infected with EPEC in hospital. The study was made during a hospital epidemic caused by the 0126:K71B16 serotype; for this serotype the proportion of children

Received 7 October 1974. infected in hospital was $94 \%$. In 36 children there were other disorders as listed in Table II.

Table III shows the treatments used before fosfomycin. In 32 children $(79 \%)$ an antibiotic had been used and in 19 of these the treatment lasted more than a week without obtaining any clinical or bacteriological improvement.

Treatment and dosage. The fosfomycin calcium salt was used as a suspension containing $50 \mathrm{mg} / \mathrm{ml}$ of active product. It was given orally as the only antibiotic, in doses of 100 or $200 \mathrm{mg} / \mathrm{kg}$ per day divided into 3 or 4 units for an average of 7 days.

Bacteriological study. The selection and diagnosis of all the cases were made by stool culture and immunofluorescence. The following culture media were used: MacConkey agar, Selenite broth, SS agar, MRS agar, Mycobiotic agar, and Mannitol-Salt agar. Colony counts were made on fresh specimens of faeces, which were homogenized and then diluted $1 / 10$ to $1 / 10000 ; 0.05 \mathrm{ml}$ of each dilution were plated out on Cysteine-Lactose-Electrolyte-Deficient agar (Oxoid). The direct immunofluorescence examination was made on the $1 / 10$ dilution of the faeces using polyvalent antisera conjugated to fluorescein isothiocyanate, contrast stained by rhodamine.

EPEC serotyping was done with antisera using the 
TABLE I

Characteristics of the patients studied

\begin{tabular}{|c|c|c|c|c|c|c|c|c|}
\hline \multirow[b]{2}{*}{ Sex } & \multicolumn{4}{|c|}{ Age (d) } & & \multicolumn{2}{|c|}{ Age (m) } & \multirow[b]{2}{*}{ Total } \\
\hline & $0-10$ & $11-20$ & $21-30$ & $31-60$ & $61-90$ & $3-12$ & 12 & \\
\hline $\begin{array}{l}\text { Males } \\
\text { Females }\end{array}$ & $\begin{array}{l}2(1) \\
1(1)\end{array}$ & $\begin{array}{l}5(2) \\
3(2)\end{array}$ & $\begin{array}{l}6(4) \\
7(6)\end{array}$ & $\begin{array}{l}4 \\
5(1)\end{array}$ & $\begin{array}{l}3 \\
2\end{array}$ & $\begin{array}{l}2 \\
1\end{array}$ & 1 & $\begin{array}{l}22(7) \\
20(10)\end{array}$ \\
\hline Total & & & & & & & & $42(17)$ \\
\hline
\end{tabular}

\begin{tabular}{l|c|c}
\hline Clinical states & Primary cases & Secondary cases \\
\hline Serious & 18 & - \\
Mild & 21 & 11 \\
Carriers & 3 & - \\
\hline
\end{tabular}

Numbers in parentheses indicate prematures.

TABLE II

\section{Concomitant states}

Digestive apparatus

Intestinal malrotation 2; postoperative omphalocele 1 ; oesophageal atresia 1 ; anal atresia 1 ; megacolon 1 ; malabsorption dystrophy 2

Circulatory-respiratory apparatus

Pre/postoperative cardiopathy with/without hepatomegaly 3 ; pulmonary agenesis 1 ; transposition of main arteries 1

\section{Infections}

Bronchopneumonia 3; otitis 5; pharyngeal carriers of Pseudomonas 2; bacteriuria by EPEC and Enterobacter 1; hepatitis 1; sepsis by Esch. coli 1;

Nervous system

Cerebral postanoxic paralysis 1

Others

Mongolism 1; hypocalcaemia 1; rickets 3; anti-D isoimmunization 1; transfusion reaction 1; hydrocele 2

TABLE III

Previous antibiotic treatments in 42 patients

\begin{tabular}{l|r}
\hline & No. (\%) \\
\hline No previous antibiotic treatment & $3(7 \cdot 1)$ \\
Antibiotic treatment unrelated to gastroenteritis & $6(14 \cdot 3)$ \\
Previous treatment for gastroenteritis & $32(78 \cdot 6)$ \\
& \\
Nature of previous treatment & 12 \\
Colistin alone & 11 \\
Colistin and nifuroxazide & 5 \\
Nifuroxazide and nalidixic acid & 4 \\
Sulphonamides-neomycin & \\
\hline
\end{tabular}

method of the Pasteur Institute (Le Minor, 1972). Polyvalent $O B$ and specific $O B / O$ antisera were used; for the latter, the minimum agglutinating values were $1: 200$ for the $O$ titre and 1:1600 for the B titre.
The antibiotic sensitivity of the strains to fosfomycin, other antibiotic and chemotherapeutic agents, was examined by the disc-plate test. The minimum inhibitory concentrations (MIC) of each strain to fosfomycin was determined by the agar dilution method using techniques recommended by WHO (Ericsson and Sherris, 1971). An inhibition zone of $10 \mathrm{~mm}$ round a $30 \mu \mathrm{g}$ disc was considered to be the minimum reflecting a therapeutic response to the antibiotic. The criteria recommended by the suppliers (Pasteur Institute) were followed for the other antibiotics. Bacteriological examination of the faeces was repeated every 3 days during the course of treatment, 3 days after ending it, and afterwards between the first and fourth weeks.

Fosfomycin determinations. Determinations of fosfomycin in blood and faeces were made using a platediffusion microbiological method with MB-1159 Erwinia atroseptica as the test organism $(H$. Wallick and W. Maiese, personal communication, 1969). Concentrations for the standard curve were $0.5,0.75,1 \cdot 0,1 \cdot 5$, and $2 \cdot 0$ $\mu \mathrm{g} / \mathrm{ml}$, and dilutions were made in human serum or $p H$ 8.0 Tris buffer $(0.05 \mathrm{~mol} / \mathrm{l})$ depending upon the assay. Serum samples were diluted in human serum and stool samples in buffer to approximately $1.0 \mu \mathrm{g} / \mathrm{ml}$. At the working dilutions no stool bacterial interference was seen in the determinations.

Evaluation criteria and secondary infections. We call mild cases those which do not require intravenous fluids and serious cases those needing intravenous drips and frequently having electrolyte disturbances. The criteria of cure were based on the following parameters : the remission of diarrhoea, recovery of lost weight, and elimination of EPEC from faeces. When EPEC were eliminated without clinical response, there was said to be a bacteriological cure. A failure was recorded when there was neither a clinical nor a bacteriological cure. Reinfections were considered to be those cases in which a different serotype or antibiotype of EPEC was 
TABLE IV

Distribution by serotypes of the 57 strains of EPEC isolated

\begin{tabular}{|c|c|c|c|c|}
\hline \multirow{2}{*}{ Serotypes } & \multicolumn{2}{|c|}{ Primary cases } & \multirow{2}{*}{$\frac{\text { Secondary cases }}{1 \text { Type only isolated }}$} & \multirow{2}{*}{ Total (\%) } \\
\hline & 1 Type only isolated & 2 Types isolated & & \\
\hline $\begin{array}{l}018: \mathrm{K} 21 B 75 \\
055: \mathrm{K} 59 B 5 \\
0111: \mathrm{K} 58 B 4 \\
0119: \mathrm{K} 69 \mathrm{~B} 14 \\
0125: \mathrm{K} 70 \mathrm{~B} 15 \\
0126: \mathrm{K} 7 \mathrm{~B} 16\end{array}$ & $\begin{array}{r}-1 \\
12 \\
4 \\
2 \\
19\end{array}$ & $\frac{-}{-}$ & $\begin{array}{l}2 \\
1 \\
2 \\
1 \\
5\end{array}$ & $\begin{array}{c}2(3) \\
2(3) \\
14(25) \\
5(9) \\
6(11) \\
28(49)\end{array}$ \\
\hline \multirow[t]{2}{*}{ Total strains } & 38 & 8 & 11 & $57(100)$ \\
\hline & $\begin{array}{c}38 \\
(90 \cdot 5 \%)\end{array}$ & $\begin{array}{c}4 \\
(9.5 \%)\end{array}$ & 11 & \\
\hline Total cases & \multicolumn{2}{|c|}{42} & 11 & 53 \\
\hline
\end{tabular}

found. When the EPEC in the faeces had the same serotype and antibiotype, then it was considered to be relapse.

\section{Results}

Microbiological study. All the stool cultures of treated children grew EPEC. In 4 cases there was a mixed infection with two different serotypes. The 57 EPEC strains found were distributed (Table IV) throughout 6 different serotypes, the most frequent being 0126:K71B16 (49\%) and 0111: K58B4 (25\%).

The quantitative stool cultures and the direct immunofluorescence gave congruent results. In the primary infections the average participation colony count of EPEC in relation to the total count of aerobic-bacterial flora was $76 \%$, including 14 cases in which EPEC in pure culture was isolated. The EPEC count varied between $10^{8}$ and $10^{10}$ colonies/g faeces. In the secondary infections, however, the participation of EPEC in relation to the total aerobic-bacterial flora was smaller ( $41 \%$ average), the counts also being lower than in the primary infections. In $66 \%$ of the stool cultures made before treatment, in addition to EPEC, there were small numbers of Enterobacter, Streptococcus faecalis, and nonserotyped Esch. coli (Table V).

The sensitivity of the 57 EPEC strains found at the beginning of the treatment to fosfomycin and other antibiotics and chemotherapy agents is summarized in Table VI. Gentamicin and fosfomycin are the most active agents. In the Fig. it can be seen that all the fosfomycin-sensitive

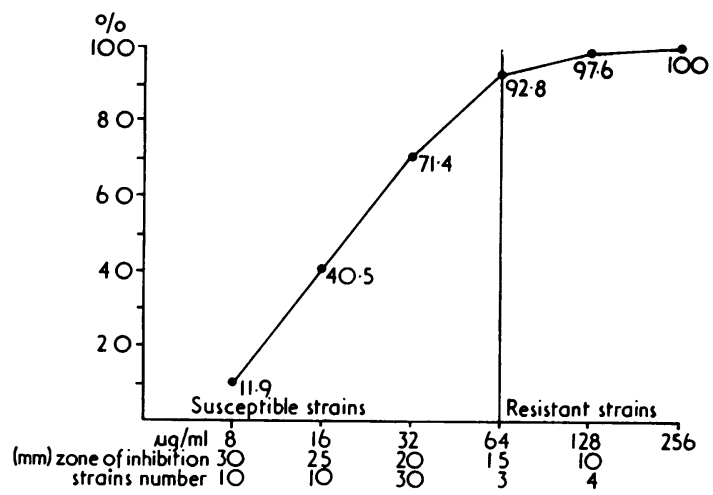

FIG.-Cumulative percentages of the values of minimal inhibitory concentrations of strains of EPEC isolated, and correlation with the diameter of the zone of inhibition.

TABLE V

Accompanying intestinal flora

\begin{tabular}{l|c|c|c|}
\hline \multicolumn{1}{c|}{ Organism } & $\begin{array}{c}\text { Before } \\
\text { treatment (\%) }\end{array}$ & $\begin{array}{c}3 \text { days after } \\
\text { treatment (\%) }\end{array}$ \\
\hline Esch. coli nonserotyped & $11 \cdot 3$ & $52 \cdot 1$ & $67 \cdot 3$ \\
Enterobacter cloacae & $52 \cdot 8$ & $31 \cdot 3$ & $71 \cdot 0$ \\
Streptococcus faecalis & $34 \cdot 0$ & $23 \cdot 2$ & \\
\hline
\end{tabular}

Note: The percentages in this table correspond to the cases from whose stools the indicated organisms were isolated. 
TABLE VI

Susceptibility of 57 strains of EPEC isolated from 42 primary cases and 11 secondary cases

\begin{tabular}{l|c|c}
\hline $\begin{array}{c}\text { Antibiotic or } \\
\text { chemotherapeutic }\end{array}$ & $\begin{array}{c}\text { Concentration of } \\
\text { disc }(\mu \mathrm{g})\end{array}$ & $\begin{array}{c}\% \text { of susceptible } \\
\text { strains }\end{array}$ \\
\hline Gentamicin & 30 & 100 \\
Fosfomycin & 30 & $93 \cdot 0$ \\
Nitrofurantoin & 300 & $88 \cdot 1$ \\
Colistin & 10 & $69 \cdot 7$ \\
Nalidixic acid & 30 & $57 \cdot 1$ \\
Cephalothin & 30 & $52 \cdot 4$ \\
Tetracycline & 30 & $21 \cdot 4$ \\
Novobiocin & 30 & $14 \cdot 3$ \\
Erythromycin & 15 & $9 \cdot 5$ \\
Neomycin & 30 & 440 \\
Streptomycin & 30 & $2 \cdot 4$ \\
Kanamycin & 30 & $2 \cdot 4$ \\
Carbenicillin & 100 & 0 \\
Ampicillin & 25 & 0 \\
Chloramphenicol & 30 & 0 \\
Sulphonamides & 50 & 0 \\
& & \\
\hline
\end{tabular}

*Ordinarily the percentage susceptibility to colistin of the EPEC strains is greater than this in the clinic.

strains had an MIC of $64 \mu \mathrm{g} / \mathrm{ml}$ or less, with an inhibition zone diameter bigger than $10 \mathrm{~mm}$; only the 4 strains resistant to $30 \mu \mathrm{g}$ fosfomycin disc exceeded this value. These were strains of Esch. coli type 0111:K58B4 and in spite of their comparative in vitro resistance, they were eliminated from the faeces with the same ease as the sensitive strains, probably because the concentrations of active fosfomycin in the intestinal tract were much greater than the MIC values of the strains. In all cases, primary and secondary, oral administration of fosfomycin was followed by the elimination of EPEC from the faeces within 3 days of treatment. Secondary infections appeared 2 weeks after stopping treatment and then only in children who for other reasons had stayed in hospital, EPEC being found again in the stool cultures of 11 children.

According to our criteria, out of the 11 secondary infections we considered 6 to have reinfections $(14 \%)$ and 5 relapses $(12 \%)$. All cases developed mild diarrhoea.

Bacteriological studies showed (Table V) that the action of fosfomycin was specific against the causal micro-organism (EPEC) without appreciably altering the rest of the bacterial flora. It is difficult to explain why nonpathogenic Esch. coli were selected during the fosfomycin treatment. The selection of $E$. cloacae could be based on the frequent resistance of this species to fosfomycin.

Fosfomycin blood and faecal concentrations. Table VIIA shows the results of blood levels in two groups of children treated with doses of fosfomycin of 100 and $200 \mathrm{mg} / \mathrm{kg}$ per day. Though after the first dose the group of children treated with the smaller dose had an average blood level lower than the second group treated with twice the dose, after a few days of treatment the first group, who were all premature babies, showed levels much higher than

TABLE VII

(A) Blood levels after oral administration of fosfomycin

\begin{tabular}{|c|c|c|c|c|}
\hline \multirow{3}{*}{ Treatment and dosage } & \multicolumn{4}{|c|}{ Average blood levels $(\mu \mathrm{g} / \mathrm{ml})$} \\
\hline & \multicolumn{3}{|c|}{ After the 1st dose (h) } & \multirow{2}{*}{$\begin{array}{l}\text { During treatment on } \\
\text { 3rd to } 7 \text { th } \mathrm{d}: 1 \mathrm{~h}\end{array}$} \\
\hline & 1 & 2 & 6 & \\
\hline $\begin{array}{l}11 \text { patients (8 prematures) } \\
100 \mathrm{mg} / \mathrm{kg} \text { per day in doses of } 25 \mathrm{mg} / \mathrm{kg} \\
\mathrm{SD}\end{array}$ & $\begin{array}{l}2 \cdot 8 \\
(0 \cdot 6)\end{array}$ & $\begin{array}{l}2 \cdot 9 \\
0 \cdot 7)\end{array}$ & $\begin{array}{c}2 \cdot 7 \\
(0 \cdot 9)\end{array}$ & $\begin{array}{l}14 \cdot 2 \\
(2 \cdot 3)\end{array}$ \\
\hline $\begin{array}{l}12 \text { patients } \\
200 \mathrm{mg} / \mathrm{kg} \text { per day in doses of } 50 \mathrm{mg} / \mathrm{kg} \\
\text { SD }\end{array}$ & $\begin{array}{c}4 \cdot 6 \\
(1 \cdot 6)\end{array}$ & $\begin{array}{c}4 \cdot 3 \\
(0 \cdot 5)\end{array}$ & $\begin{array}{c}3 \cdot 4 \\
(0 \cdot 4)\end{array}$ & $\begin{array}{c}7 \cdot 8 \\
(0 \cdot 9)\end{array}$ \\
\hline
\end{tabular}

(B) Fosfomycin concentration in faeces

\begin{tabular}{c|c}
\hline \multicolumn{1}{c|}{ Treatment and dosage } & Average of 11 cases on 3-4th d of treatment \\
\hline $\begin{array}{c}11 \text { patients } \\
200 \mathrm{mg} / \mathrm{kg} \text { per day in doses of } 50 \mathrm{mg} / \mathrm{kg}\end{array}$ & $\begin{array}{c}3 \cdot 7 \mathrm{\mu g} / \mathrm{g}, \text { faeces just eliminated (maximum value } 8 \cdot 55 \mathrm{\mu g} / \mathrm{g} ; \mathrm{minimum} \mathrm{value} \\
1.33 \mu \mathrm{g} / \mathrm{g} \text { ) }\end{array}$ \\
\hline
\end{tabular}

$\mathrm{SD}_{\mathrm{c}}$ standard deviation. 
TABLE VIII

Summary of results

\begin{tabular}{l|c|c|}
\hline & $\begin{array}{c}\text { Primary cases (and \%) } \\
\text { (18 serious, 21 mild, } \\
\text { and 3 carriers) }\end{array}$ & $\begin{array}{c}\text { Secondary cases (and \%) } \\
\text { (all mild; 6 reinfect- } \\
\text { ions and 5 relapses) }\end{array}$ \\
\hline $\begin{array}{l}\text { Patients treated } \\
\text { Bacteriological cures }\end{array}$ & $\begin{array}{c}\text { Total } \\
\text { (\%) }\end{array}$ & $\begin{array}{c}11(100) \\
11(100)\end{array}$ \\
Clinical cures & $32(100)$ & $53(100)$ \\
$11(100)$ & $53(100)$ & $49(92 \cdot 4)$
\end{tabular}

$\star$ The 4 remaining cases were given successful corrective dietetic treatment for symptoms of malabsorption.

those of the second group, no doubt due to the accumulation of fosfomycin due to the physiological renal insufficiency in premature children.

In another group of 11 children, treated with $200 \mathrm{mg} / \mathrm{kg}$ per day given in 4 doses (Table VIIB) the concentration of fosfomycin in faeces was determined. It was not intended to study quantitatively elimination through the rectal route, but to determine the active antibiotic concentration.

Clinical results. Table VIII summarizes the results of fosfomycin treatment of $\mathbf{4 2}$ patients who received a total of 53 treatments. Though EPEC was always eliminated quickly, in 4 cases diarrhoea only ceased after adequate dietary treatment. The 11 secondary infections all responded well to a second course of fosfomycin, with no appreciable development of EPEC resistance to it: in one case EPEC MIC increased from 8 to $64 \mu \mathrm{g} / \mathrm{ml}$. Clinical progress was excellent in all patients, except for the 4 mentioned above, and the general condition improved rapidly, even in the seriously ill patients. The stools became normal in nature and frequency after the third day of treatment. Excluding the 3 carriers, the average number of stools fell from 7 per day before treatment to 3 per day after. Weight, which was decreasing or static before treatment, increased gradually as the children improved and diarrhoea stopped. The average increase was $7 \cdot 4 \%$ at the end of treatment, and $13.4 \%$ for the 17 premature children.

Fosfomycin was shown to be more active in vivo than in vitro, since the 4 EPEC initially resistant were also eliminated, owing no doubt to the high fosfomycin concentrations obtained in situ, far exceeding the MIC of these micro-organisms. The results did not appear to differ according to the dosage used (100 or $200 \mathrm{mg} / \mathrm{kg}$ per day).

Tolerance and toxicity. There were no side effects, superinfections, or candidiasis, and no evidence of toxicity from the blood analysis data. Transaminase levels did not change with fosfomycin treatment, since the average SGOT values before, during, and after treatment were 46,47 , and 49 Reitman-Frankel units and SGPT 31, 36, and 30 Reitman-Frankel units. In no case did we find any increase in the values of transaminase, urea, creatinine, and alkaline phosphatase.

\section{Discussion}

The treatment of intestinal bacterial infections with antibiotics was questioned by Dixon (1965) and Aserkoff and Bennett (1969), who noted a longer period of excretion of the pathogenic flora in the treated patients than in nontreated ones. Technical progress in fluid replacement and in the general care of the child with diarrhoea have considerably improved the prognosis of these patients, but we believe that antibiotic therapy can improve it further, especially in the acute phase of the disease. In the intestinal invasive growth phase of EPEC, antibiotics can probably reduce the pathogenic EPEC population and so the total amount of enterotoxin produced, decreasing the pathophysiological effects of this substance. Also, as the pathogenic EPEC population is reduced in the baby, antibiotic therapy could help prevent acute epidemic dissemination, which is very important in children's hospitals.

It is possible that the wide spectrum antibiotics, especially high doses, cause suppression of the normal antagonist flora permitting a possible superinfection, relapse, or reinfection. The possibility of affecting the normal antagonist flora is probably more important in the subacute or chronic phase of the disease corresponding to the spontaneous resettlement of this flora. This could explain the negative effect of the prolonged antibiotherapy in the proportion of carriers of enteropathogenic organisms after the acute bacterial diarrhoea. Haltalin, Nelson, and Kusmiesz (1973) have shown the necessity of using absorbable antibiotics in the treatment of shigellosis, and the same may be true for some EPEC gastroenteritis.

Because fosfomycin is absorbed it provides therapeutic serum levels and a high intraluminal con- 
centration in active form. With the dose used, it eliminates EPEC rapidly from the stool without appreciably altering the normal enteric flora. The EPEC strains found were sensitive to fosfomycin and no appreciable EPEC resistance developed in the 53 treatments. Hendlin et al. (1970) showed that the development of resistance to fosfomycin in vitro is of a chromosomal nature and that the resistant strains are defective metabolic mutants that lose the original virulence of the pathogenic strains: they cannot transfer in vitro their bacterial resistance to fosfomycin, indicating that this is not of a plasmidic nature. This antibiotic was well accepted and tolerated by children and no toxicity was detected. Fosfomycin can be considered to be a valuable antibiotic for the treatment and epidemiological control of EPEC infections in hopitalized children.

\section{REFERENCES}

Aserkoff, B., and Bennett, J. V. (1969). Effect of antibiotic therapy in acute salmonellosis on the fecal excretion of Salmonellae. New England Fournal of Medicine, 281, 636.

Dixon, J. M. S. (1965). Effect of antibiotic treatment on duration of excretion of Salmonella typhimurium by children. British Medical fournal, 2, 1343.

Ericsson, H. M., and Sherris, J. C. (1971). Antibiotic sensitivity testing. Acta Pathologica et Microbiologica Scandinavica, Sect. B., Suppl. 217.

Foltz, E. L., Wallick, H., and Rosenblum, C. (1970). Pharmacodynamics of phosphonomycin after oral administration in man. Antimicrobial Agents and Chemotherapy, 1969, p. 322. Ed. by G. L. Hobby. American Society of Microbiology, Bethesda, Maryland.

Haltalin, K. C., Nelson, J. D., and Kusmiesz, H. T. (1973). Comparative efficacy of nalidixic acid and ampicillin for severe shigellosis. Archives of Disease in Childhood, 48, 305.

Hendlin, D., Stapley, E. O., Jackson, M., Wallick, H., Miller, A. K., Wolf, F. J., Miller, T. W., Chaiet, L., Kahan, F. M., Foltz,
E. L., Woodruff, H. B., Mata, J. M., Hernandez, S., and Mochales, S. (1969). Phosphonomycin: a new antibiotic produced by strains of Streptomyces. Science, 166, 122.

Hendlin, D., Frost, B. M., Thiele, E., Kropp, H., Valiant, M. E., Pelak, B., Weissberger, B., Cornin, C., and Miller, A. K. (1970). Phosphonomycin: evaluation in vitro. Antimicrobial Agents and Chemotherapy, 1969, p. 297. Ed. by G. L. Hobby. American Society for Microbiology, Bethesda, Maryland.

Kestle, D. G., and Kirby, W. M. M. (1970). Clinical pharmacology and in vitro activity of phosphonomycin. Antimicrobial Agents and Chemotherapy, 1969 , p. 332. Ed. by G. L. Hobby. American Society for Microbiology, Bethesda, Maryland.

Le Minor, L. (1972). Le diagnostic de laboratoire des bacilles a gram négatif. Enterobacteries, 4th ed., p. 99. Ed. by de la Tourelle.

Martin, I., Mochales, S., Hernandez, S., Rodriguez, A., and Mata, J. M. (1970). Estudios de sensibilidad bacteriana frente a la fosfonomicina. Anules del Instituto de Farmacologia Española, $19,327$.

Miller, A. K., Frost, B. M., Valiant, M. E., Kropp, H., and Hendlin, D. (1970). Phosphonomycin: evaluation in mice. Antimicrobial Agents and Chemotherapy, 1969, p. 310. Ed. by G. L. Hobby. American Society for Microbiology, Bethesda, Maryland.

Moreno-Lopez, M., Dámaso, D., Perea, E. J., Sousa, A. S., Martinez., M. L., and Marco, M. L. (1971). Phosphonomycin: quantitative sensitivity spectra of various hospital strains to this new antibiotic. Microbiologia Española, 24, 79.

Rodriguez, A., and Mata, J. M. (1968-1969). Datos farmacodinámicos sobre la administración de la fosfonomicina en el hombre por las vias intramuscular y oral. Anales del Instituto de Farmacologia, 17-18, 439.

Stapley, E. O., Hendlin, D., Mata, J. M., Jackson, M., Wallick, H., Hernandez, S., Mochales, S., Currie, S. A., and Miller, R. M. (1970). Phosphonomycin: I. Discovery and in vitro biological characterization. Antimicrobial Agents and Chemotherapy, 1969 , p. 284 . Ed. by G. L. Hobby. American Society for Microbiology, Bethesda. Maryland.

Zimmerman, S. B., Stapley, E. O., Wallick, H., and Baldwin, R. (1970). Phosphonomycin: susceptibility testing method and survey. Antimicrobial Agents and Chemotherapy, 1969, p. 303. Ed. by G. L. Hobby. American Society for Microbiology, Bethesda, Maryland.

Correspondence to Dr. F. Baquero. Ardemans $62-3^{\circ}$, Madrid 28, Spain. 